\title{
Re-integrating ecology into integrated landscape approaches
}

\author{
James Reed (D) Koen Kusters · Jos Barlow • Michael Balinga $\cdot$ Joli Rumi Borah • \\ Rachel Carmenta • Colas Chervier • Houria Djoudi • Davison Gumbo • \\ Yves Laumonier • Kaala B. Moombe - Elizabeth L. Yuliani - Terry Sunderland
}

Received: 24 July 2020/Accepted: 18 May 2021 / Published online: 26 May 2021

(C) The Author(s) 2021

\begin{abstract}
Context Integrated landscape approaches (ILAs) that aim to balance conservation and development targets are increasingly promoted through science, policy, and the donor community. Advocates suggest that ILAs are viable implementing pathways for addressing global challenges such as biodiversity loss, poverty alleviation, and climate change mitigation and adaptation. However, we argue that recent advances in ILA research and discourse have tended to emphasize the social and governance dimensions, while over-
\end{abstract}

J. Reed $(\bowtie) \cdot$ H. Djoudi · Y. Laumonier ·

E. L. Yuliani · T. Sunderland

Center for International Forestry Research, Bogor,

Indonesia

e-mail: j.reed@cgiar.org

K. Kusters

Tropenbos International, 6717 LT Ede,

Gelderland, The Netherlands

\section{J. Barlow}

Lancaster Environment Centre, Lancaster University,

Lancaster, UK

\section{Balinga}

Tetra Tech ARD - West Africa Biodiversity and Climate

Change (WA-BiCC) Program, Accra, Ghana

\section{J. R. Borah · T. Sunderland}

Faculty of Forestry, University of British Columbia,

Vancouver, Canada looking ecological factors and inadequately considering potential trade-offs between the two fields.

Objectives By raising the issue of inadequate integration of ecology in ILAs and providing some general design suggestions, we aim to support and incentivise better design and practice of ILAs, supplementing existing design principles.

Methods In this perspective we draw on the recent literature and our collective experience to highlight the need, and the means, to re-integrate ecology into landscape approaches.

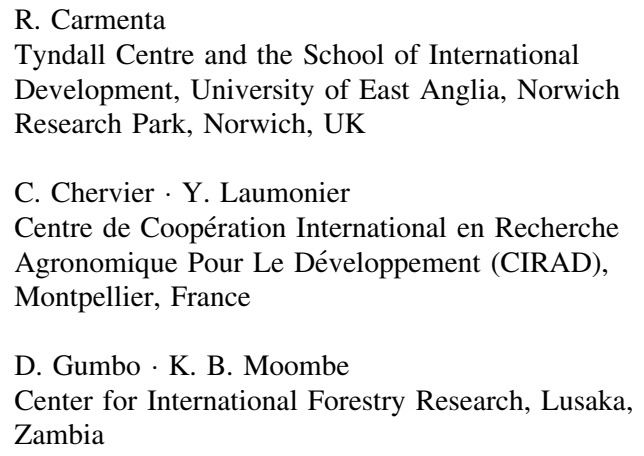


Results We suggest that better incorporation of the ecological dimension requires the integration of two approaches: one focusing on conventional scientific studies of biodiversity and biophysical parameters; and the other focusing on the engagement of relevant stakeholders using various participatory methods. We provide some general guidelines for how these approaches can be incorporated within ILA design and implementation.

Conclusion Re-integrating ecology into ILAs will not only improve ecological understanding (and related objectives, plans and monitoring), but will also generate insights into local and traditional knowledge, encourage transdisciplinary enquiry and reveal important conservation-development trade-offs and synergies.

Keywords Landscape approaches - Biodiversity conservation · Social-ecological systems · Convention on biological diversity - Ecosystem restoration . Landscape ecology

\section{Introduction}

The persistent global challenges of biodiversity loss and food insecurity have led the scientific community to identify solutions that inform the development of more sustainable land-use policies. As single-sector approaches have fallen out of favor due to their inability to decouple economic growth from environmental degradation (Godfray et al. 2010; Foley et al. 2011; Tscharntke et al. 2012), more integrated solutions have increasingly been sought (Kremen and Merenlender 2018). Approaches that integrate objectives at the landscape scale have gained increasing support in the contemporary conservation and development discourse (Defries and Rosenzweig, 2010; Sayer et al. 2013) and feature prominently in global policy debates and conventions for climate, food security, biodiversity and broader sustainable development.

These increasingly people-centered approaches to land management attempt to provide a more balanced mechanism for addressing multiple and often competing interests inherent within complex, multifunctional landscapes. They are primarily characterised by integrated landscape approaches (ILAs) that seek to reconcile conservation and development objectives by facilitating dialogue between relevant stakeholders, knowledge-holders, landholders, and power-holders (hereafter stakeholders) to identify trade-offs and optimize synergies that enhance landscape sustainability and multifunctionality (Reed et al. 2016). By adopting both a broader spatial and disciplinary focus that better considers real-world complexity across a wider range of sectors and stakeholders, the perception is that over time, system threats, thresholds and feedbacks can be better understood. As such the ambition is for "more winners" and "fewer losers" in any given landscape scale context (Sayer et al. 2015b). An approach that seeks to overcome disciplinary barriers (Barlow et al. 2011; Sunderland et al. 2017) and encourages sustained stakeholder interaction and involvement (Reed et al. 2019) offers a number of practical and technical advantages (Lang et al. 2012; Norström et al. 2020).

The term "integrated landscape approach" first appeared in the literature in the early 1980s (Noss 1983), although certain core principles of the concept have been acknowledged and practised for far longer (see Reed et al. 2016). Since the 1980s, the term has become increasingly prevalent in both the conservation and development lexicons. However, despite their relatively long evolution there remains no universally agreed definition for integrated landscape approaches (Sayer et al. 2013). Perhaps surprisingly, there has also been very little discussion or debate over how to define and characterise ILAs within the scientific literature (Erbaugh and Agrawal 2017). This is despite the fact that we, as a community who have worked on these issues over the last decade or so, have frequently been asked to provide a definition when presenting our research or participating in stakeholder workshops. Advances in characterising a typology of common attributes and distinguishing features have recently been developed (Carmenta et al. 2020), nevertheless it has been pointed out that a degree of conceptual ambiguity is useful and has likely helped ILAs to generate widespread appeal (Reed et al. 2020a, b). This is primarily due to the fact there are a multitude of approaches (Scherr et al. 2013), and the commitment to being non-prescriptive and contextualized has led to the approach being variably conceived and designed, and subsequently applied. While this is positive, a lack of definition also implies a lack of basic norms and rules to follow (Mansourian, 2018; Chazdon et al. 
2020). This has made the effectiveness of ILAs difficult to evaluate and compare, has complicated the transfer of lessons and evidence-based practices, and has arguably led to conceptually weak and poorly designed implementation efforts due to the inability to follow best practice (Reed et al. 2017a, b).

While a definition for ILAs has been elusive, there is a general acceptance of some components of the term. While the term "landscape" itself is open to interpretation and will be seen in the eye of the beholder (Meinig 1979), there is reasonable consensus that it is at the scale of landscape that many socioeconomic, cultural, political and environmental issues intersect and it therefore provides a workable spatial unit for management and/or intervention (Antrop 2000; Tress et al. 2001; Antrop 2006; Milder et al. 2012). There is also increasing recognition that there are advantages of using river catchments as focal points, facilitating the integration of aquatic conditions into efforts ${ }^{1}$ (Leal et al. 2020). The 'approach' part of the term implies flexibility and ILAs have been promoted as thinking beyond project cycles with no fixed, and arguably constraining, short-term objectives (Sayer and Wells 2004)—although short-term funding cycles remain a barrier. Rather, they should be longterm iterative processes that can adapt to change and reconcile multiple objectives for the greatest possible shared benefits-a journey rather than a destination, implying the usefulness of process over rigid outcome indicators. 'Approach' also refers to the range of tools and concepts that implementing agencies elect to apply. So, while there is reasonable understanding of the "landscape" and "approach", the integrated part might be the most important component to consider, but perhaps the most overlooked. In short, what exactly should be integrated in an integrated landscape approach?

At the most basic level, the obvious focus on integration would be to reconcile different functions within a landscape, including the production of agricultural, fishery, and forestry products, biodiversity conservation, and the provision of environmental (including cultural and recreational) services. This, in turn, requires integrating different objectives across various scales of influence (Brown 2003; Cash et al. 2006). For example, ministries of agriculture, forestry

\footnotetext{
$\overline{1}$ https://www.fondosdeagua.org/en/the-water-funds/.
}

or environment will have differing opinions, bargaining power-and mandates-for balancing different land-uses and defining regulations. Likewise, land-use conflicts, for example those between pastoralists and smallholder farmers have been commonplace in West Africa (and elsewhere), for decades (Shettima and Tar 2008).

A key distinction of ILAs, relative to previous attempts to reconcile conservation and development objectives was the explicit acknowledgement of such trade-offs (Sunderland et al. 2008; McShane et al. 2011). Whereas previous initiatives tended towards unfulfilled promises of win-win outcomes, proponents of ILAs stress that while win-wins are desirable, when faced with complex, 'messy', local realities, trade-offs will be the norm (Sayer 2009). A body of evidence rapidly developed that emphasized that trade-offs within landscape-scale management can, and often will, occur between biodiversity and ecosystem services, socio-economic and conservation objectives (McShane et al. 2011). There was also recognition that trade-offs could include the more intangible gains and losses such as those related to the multi-dimensional well-being of vulnerable or marginalized stakeholders (Daw et al. 2015; ESPA 2018). Despite these advances, we are concerned by an inadequate consideration of trade-offs in recent ILA discourse and literature and, in particular, insufficient attention paid to the ecological dimension, with a rhetoric shifting back towards that of win-win outcomes for both people and nature. At face value, this may appear ostensibly for the good, but evidence has shown that, overall, such win-win outcomes are highly elusive (Christensen 2004; Muradian et al. 2013) and that in "integrating conservation and development there are winners and losers" (Brown 2004 p. 232)-i.e. there will be trade-offs.

Our concern is that the failure to acknowledge trade-offs then influences subsequent application and will likely result in unrealized synergies and perverse outcomes leading to poor impacts on either people or nature, or worse, both. That is not to say that that there must be an either/or choice between people and nature (i.e. further reverting back to a fortress conservation model), but that the future application of ILAs must be grounded in empirical information that better considers what it means to have enhanced integration and the implications of doing so. While we acknowledge that a more thorough examination of the extent of 
integration in ILAs is needed, our intention here is to highlight one contemporary feature - that is the fading emphasis on the ecological dimension within recent scholarship on ILAs. To that end, we offer a set of criteria consisting of general guidelines that can help re-integrate ecology and aid the design and monitoring of ILAs.

\section{The ecological dimension}

Motivations for, and approaches to, conserving biodiversity have varied historically (Adams et al. 2004; Mace 2014) and continue to do so (Büscher and Fletcher 2019; Sandbrook et al. 2019). As such, there has been something of a pendular swing of emphasis shifting between the natural and social sciences (Oates 1999; Doak et al. 2013; Soulé 2013; Sandbrook 2015; Mansourian and Parrotta 2018). Meanwhile more collaborative approaches emerged to address the lack of disciplinary integration (Tress et al. 2001; Fischer et al. 2008; Scherr and McNeely 2008), though many initially remained heavily rooted in the natural sciences, encouraged by the fast-growing discipline of landscape ecology (Wu 2013)—itself a discipline that has grappled with the question of what to integrate, and to what extent (Mansourian 2021). Such approaches were primarily concerned with for example, landscape connectivity, species diversity and ecological assessment (Bourgeron et al. 2001; Gutzwiller 2002; Fischer et al. 2006; Lindenmayer et al. 2008). Recognizing the relative absence of people, politics, and broader societal concerns in such endeavours, and acknowledging that such absence likely contributed to sub-optimal outcomes, Sayer et al. (2013) developed ten principles to guide future application of integrated landscape approaches. These principles and guidelines were explicit in their attempt to highlight the important role of local people, and the inclusion of governance and institutions. These are critical factors to consider in the pursuit of landscape sustainability and a valuable contribution to the literature. Likewise, greater emphasis on the social impacts of conservation and natural resource management (NRM) interventions (Sandbrook et al. 2013; Hicks et al. 2016; Charnley et al. 2017) and the recognition of local people's perceptions of such interventions (Bennett 2016) is most welcome, and necessary.
While these endeavours have helped the evolution of ILAs to expand beyond singular focus on ecological dynamics, we argue that within recent scholarship on ILAs the pendulum is in danger of swinging too far into the governance and socio-political realm. For example, the ten principles, along with subsequent design frameworks (Freeman et al. 2015; Reed et al. 2016; Bürgi et al. 2017; Ros-Tonen et al. 2018) primarily refer to aims and actions (Mbow et al. 2015) and mostly relate to governance and the role of individuals, power and institutions. Likewise, recent reviews and analyses have emphasized the social impacts, governance structures and (to a lesser extent) the power relations within ILAs (Kozar et al. 2014; Clay 2016; McCall 2016; Arts et al. 2017; Bürgi et al. 2017; Reed et al. 2017a, b; Kusters et al. 2020). Similarly, scholarship identifying barriers to implementation also tends to highlight socio-political and financial, rather than ecological dimensions (Reed et al. 2016; Vermunt et al. 2020). But, practitioners and researchers of ILAs must be cautious not to overlook the equally important ecology of ILAs, lest it becomes further inadequately addressed in designing integrated options for land-use decision making and policy (Laumonier et al. 2008; Arroyo-Rodriguez et al. 2020).

Better knowledge and appreciation of the ecological dimensions inherent within landscape management is essential in order to develop appropriate, evidence-based governance responses that better balance often-competing economic priorities while mitigating environmental degradation. In doing so, ILAs can not only improve ecological outcomes but also generate insights into local and traditional knowledge, encourage transdisciplinary enquiry and reveal conservation-development trade-offs and synergies (Laumonier et al. 2008). We suggest that a re-integration of ecological principles is particularly timely as landscape approaches appear set to feature prominently in upcoming strategies for delivering globally conceived conservation and restoration targets.

\section{Challenges for integration of ecology}

Biodiversity conservation can be justified for a broad range of moral and utilitarian reasons and is prioritized in many international conventions (IPBES 2019). From a utilitarian perspective, it is accepted 
that biodiversity provides goods and services essential for sustaining human well-being (Rasmussen et al. 2017). However, the complexities of these relationships are not necessarily well-understood or quantified (Reed et al. 2017a, b), particularly within complex forest and agriculture mosaic landscapes undergoing rapid change-as found in tropical frontier landscapes (Barlow et al. 2018). As such, ecology is rarely, or inadequately, reflected in public land-use policies or final decision-making processes, beyond generic guidance that environmental aspects should be considered. In theory, ILA processes could help foster ecological understanding and considerations into decision-making processes and policies. However, one of the main challenges to integrating ecology into ILAs is related to project funding cycles, which tend to be short-term when landscape dynamics require longterm engagement and investigation. Integrating ecology is further problematized by the disciplinary specificity of the natural and social sciences as well as a poor history of reconciling traditional and scientific knowledge, in spite of the acknowledgement that local land managers often hold considerable place-based ecological knowledge (Biggs et al. 2011; Kimmerer 2013; Ban et al. 2018).

Although the majority of ILAs have explicit conservation objectives (Hart et al. 2015; Carmenta et al. 2020), the integration of ecology in ILAs is limited by a lack of understanding about the impact of human stressors on biodiversity, and the relationship between biodiversity and ecosystem services (ES) and their benefits to health and well-being in general (Cordingley et al. 2016; Gergel et al. 2020). Better integration of ecology requires the integration of two approaches: one focusing on conventional scientific studies of biodiversity and biophysical parameters; and the other focusing on the participation of relevant stakeholders, using various participatory methods to co-create options that meet multiple stakeholder needs. While effective integration of these two approaches is challenging, it should be at the core of effective policies and action on the ground over the long term, as scientific and traditional place-based knowledge of natural resource management by local people are all valuable and complementary, and diverse perceptions of impacts allows a more plural appraisal of relevant trade-offs (Zafra-Calvo et al. 2020). Therefore, the two approaches should inform one another. Results of conventional scientific studies should be shared with local land managers, and participatory methods should bring local knowledge and priorities to inform scientists and relevant decision-makers. For example, these efforts can highlight what studies are locally relevant, and what indicators could be built from local knowledge and prioritized values. Below, we provide some general guidelines and highlight some recent advances that can help to overcome some of the challenges associated with achieving improved integration.

\section{Guidelines for integrating ecology into ILA design and monitoring}

Here we discuss the general ecological approaches that could be used to support ILA design and monitoring. Ecology can play a key role when observation studies are used to quantify spatial variation in biodiversity and ecosystem services. This involves collecting or compiling data on species presence and their abundance, the ecological services they deliver, and their uses and relational values perceived by local people (Pascual et al. 2021). This information is key for understanding which aspects of the landscape have the highest ecological and social values, and which areas require interventions to improve. One approach to achieving this involves snapshot surveys of ecological condition across the region, capturing the full range of dominant land uses and land tenures (i.e. not just reserves). Such assessments need to consider what taxa are going to be sampled, which will be influenced by considerations about their vulnerability to change or rarity, their importance for local people (ecosystem services, including more intangible cultural services), and whether they are cost-effective indicators of condition (Gardner et al. 2008). As ILA's encompass multiple goals, multi-taxa, multi-scale and multi-metric sampling approaches are likely to be more revealing; biodiversity responses are affected by the scale of assessment and metric used (Solar et al. 2015), and it is important to understand to what extent targeting one goal (e.g. carbon stocks) will adequately represent other goals (e.g. biodiversity) (Ferreira et al. 2018).

Ecological studies are also key for understanding temporal changes in ecological condition (Dornelas and Magurran 2018). For example, they can quantify the role of climatic stressors in driving change 
(Esquivel-Muelbert et al. 2019) or species declines (Stouffer et al. 2021) and examine how these interact with land uses (França et al. 2020) or landscape configuration. Temporal replication also opens up the possibility of using before-after control-impact (BACI) sampling designs, which can have greater ability to detect impacts (França et al. 2016). Despite the many benefits of temporal replication, there are also challenges: long-term monitoring remains difficult to fund and sustain, and data curation is a challenge (Phillips et al. forthcoming). While some technological advance could help with this-automated sampling techniques such as camera traps and bioacoustics are developing fast (Sueur and Farina 2015) - there is often no substitute for people on the ground and expert field skills.

Ecological experiments could support ILAs by (i) allowing researchers to determine drivers and understand mechanisms which are often hard to elucidate in observational studies in complex systems, and (ii) helping predict the outcome of future events that have yet to happen. This second point is key, as landscapes are experiencing rapid and unpredictable change, and understanding past events through snapshot studies or long-term monitoring may not predict non-linear or sudden changes. Experiments can range from controlled manipulations (true experiments) or can make use of natural events that create pseudo-experimental conditions (Cunningham and Lindenmayer 2017). Although landscape-scale experiments tend to be under-used in ecology (Jenerette and Shen 2012), their potential in the tropics is exemplified by two long-running manipulations that have provided unique insights into the mechanisms underpinning environmental change in the Amazon (Laurance et al. 2011) and the Cerrado (Gomes et al. 2018).

Modelling studies can provide key information on future trajectories of landscapes, combining our current understanding of a system with predictions of climate change and/or other anthropogenic stressors (Fonseca et al. 2019). Simulation models can provide key insights that are unobtainable from empirical studies, and can identify specific factors or processes that are key to achieving conservation goals (Synes et al. 2016). Models range in complexity and scale, and can be pattern-based or process-based, depending on the understanding of the system. Agent-based models can be used to examine interactions between the environment and human decisions making (Bousquet et al. 2002; Synes et al. 2016). Ecological or environmental models can be linked to stakeholders though the use of scoping models, which can be developed in a participatory manner while retaining much of the inherent complexity of real-world landscapes (Collier et al. 2011; Voinov et al. 2018).

These approaches are not exhaustive or mutually exclusive, and there can be many benefits of combining them. Furthermore, they should be considered alongside established principles for landscape approaches (Sayer et al. 2013), governance (Lockwood et al. 2010; Mansourian 2017; Mansourian and Sgard 2019), as well as existing ecological principles (Fischer et al. 2006; Lindenmayer et al. 2008) criteria and indicators (Castaneda et al. 2001; Gutzwiller 2002; Sheil et al. 2004) and participatory monitoring and evaluation tools (Kusters et al. 2018; Guariguata and Evans 2019). And whatever approaches are taken, the relevance for informing ILA's will be enhanced if studies address applied questions that can guide management rather than more theoretical aspects of landscape ecology that may not be relevant at operational scales or on meaningful timeframes. Furthermore, ecological studies will benefit from robust information on historical changes in the landscapes, including information on climate, changes in forest cover or fire prevalence. But perhaps the greatest benefit of ecological studies will be delivered from a transdisciplinary approach that engages a range of sectors, disciplines and stakeholders from the outset that will help identify issues of most concern, any institutional, financial, and technical capacity needs, and contribute to co-developed action plans that hold high local significance. We outline these in more detail below.

\section{The need for relevant participation}

There is a large and growing body of scientific literature on landscape ecology, and an increasing number of researchers are trained to look at landscapes as social-ecological systems. We argue that the views and experiences of professional ecologists and biologists should be part and parcel of the design and monitoring of ILAs. But that alone is not enough. Public problems that contain a high level of complexity such as landscape management (i.e. multiple 
dynamic systems, multiple problems and multiple objectives, high level of risk, sociopolitical complexity, biological complexity, and scientific uncertainty) make broader stakeholder involvement an absolute necessity (Salwasser 2002; Balint et al. 2011).

Research will be more effective if knowledge is coproduced (i.e. framed as context-based, pluralistic, goal-oriented and interactive) (Norström et al. 2020). All research requires strong integration with key stakeholders, including them in research design and the identification of questions and methods from the outset. Identifying those stakeholders is important: they may range from community members (representing various groups, including women, elderly, youth, the elites including customary leaders, common members, migrants, and nomadic tribes if any), park managers, conservation biologists, quantitative and qualitative social scientists, natural resource economists, local researchers and students, government officials, and farmers. Not all stakeholders will be willing to engage in the research process, and groups of actors are rarely homogeneous, and cannot be adequately represented by a small number of individuals. Nevertheless, incorporating local stakeholders in the design and monitoring processes of projects and programmes increases empowerment, ownership, and engagement, and is therefore considered fundamental to enhancing local biodiversity conservation and development outcomes (Mcneely 2006; Norris 2008).

Engagement can also help to integrate, and sometimes temper, the expectations and demands of multiple stakeholders across various ecosystem services (Montoya et al. 2020). Local and indigenous communities are well positioned to locate species of conservation concern and identify appropriate indicators for ecosystem change-knowledge that should be recognized rather than being sidelined or repressed by conservation and development interventions (Sheil and Lawrence 2004; Lebel 2013; Padmanaba and Sheil 2013). Local stakeholders can also play a role in collecting data to monitor landscape changes through various forms of citizen science (Sayer et al. 2015a). A focus on more participatory landscape monitoring represents an important shift from the traditional expert-led monitoring systems towards a system whereby inclusiveness is embedded from design through to implementation and stakeholders evaluate while outsiders facilitate (Rietbergen-McCracken and Narayan-Parker 1998; Boedhihartono et al. 2018;
Evans et al. 2018). In this regard, ILAs can also learn from published principles for knowledge co-production and transdisciplinarity in sustainability research (Lang et al. 2012; Djenontin and Meadow 2018; Norström et al. 2020).

However, participatory landscape monitoring is challenging and requires finding a balance between scientific (both Western and traditional) precision and local aspiration and capacity that necessitates making systematic and collaborative decisions across the planning and implementation domains. Applying established principles for participatory monitoring and an emphasis on capacity building can enhance the likelihood of local stakeholders engaging in, and committing to, the ongoing monitoring and maintenance of initiatives beyond the project duration. Ultimately, local participants need to be able to take ownership of the process such that they can evaluate progress towards the goals that they themselves have helped to establish.

\section{Beyond the pendulum: towards meaningful integration}

Here, we are offering a reminder that principles of ecology must not be overlooked and reiterating that the integrative aspiration of landscape approaches must be well incorporated. Further, we argue that ILAs need to commit more radically to engaging stakeholders in co-developing ecological objectives and subsequent plans and monitoring, alongside those related to livelihoods and governance. This requires learning from, and building on, previous efforts that have tried to do so, e.g. (Loschiavo et al. 2013; Ojha et al. 2013; Sayer et al. 2016; Gurney et al. 2019). This is not only expected to result in higher levels of local ownership, effectiveness, and quality of information, but it will also help to identify trade-offs and possibilities to balance them. Moving towards ILAs that pay due attention to both ecological and socio-economic/governance aspects, while fully engaging local stakeholders, requires changes in the culture and attitude of intervening organizations.

Transdisciplinarity and interdisciplinarity are particularly key for ILA's, as spatial studies spanning a range of land tenures, or long-term monitoring studies require ongoing interaction and feedback between researchers and stakeholders. So while we are calling 
for a re-integration of the ecological dimension into ILAs, we must emphasize that it is not simply a case of shifting the pendulum back to the natural sciences; social sciences remain fundamental to address the interconnected crises of climate, biodiversity, food security, poverty and inequality (Larson et al. forthcoming). Research in landscapes can be facilitated by dissemination and feedback-results need to be regularly evaluated to assess usefulness. Can trends be detected, or is the variance in the data too great for the sampling approach to evaluate effects of changes in landscape management? Results also need to be disseminated to relevant stakeholders at regular intervals, allowing opportunities for feedback and discussion and allowing them to influence processes of adaptive management.

Bridging disciplinary and knowledge divides demands patience and an understanding and willingness to embrace differing values, experiences, ontologies, and epistemologies. Meanwhile, achieving greater coordination across sectors and between scales of governance will often require reimagining and reforming existing institutional structures. Nevertheless, engaging stakeholders in meaningful dialogue can help to build trust, determine collective goals, and develop pathways towards more sustainable futures. Enhanced stakeholder engagement improves various steps of decision making, such as problem structuring, policy evaluation, and operationalization (Langemeyer et al. 2018) and ensures long-term sustainability of the process. A consistent narrative in the discourses around landscape approaches is that the process of developing and conducting M\&E should encourage the explicit participation of local stakeholders (Sayer and Campbell 2004; Sayer et al. 2006, 2016) and ensure that they are active participants rather than merely unrecognized sources or disengaged recipients of information (Rietbergen-McCracken and NarayanParker 1998).

Recent advances and analyses have demonstrated a number of useful measures that can help accelerate progress towards enhanced integration. Multi-stakeholder platforms are increasingly applied to improve stakeholder dialogue. However, such initiatives should be cognizant of existing institutional structures and seek to enhance or complement rather than add to the often-complex matrix (Evans et al. 2021). Moreover, effective functioning will require careful planning, implementation, and monitoring (Kusters et al.
2018). Here, independent facilitation and boundary organizations that connect actor networks can be useful (Cash et al. 2003) while boundary objects (maps, models, reports etc. of common concepts) can help facilitate communication across diverse groups (Star and Griesemer 1989).

Training in interdisciplinary science and systems thinking is gradually starting to take place in university degree programs, and the advancement of such expertise will surely continue and enhance our ability to negotiate complex systems. In the meantime, the application of mixed methods for ILAs (Reed et al. 2020a, b) can help identify and meaningfully engage stakeholders within (and external to) the landscape to collaboratively build theories of change (Qiu et al. 2018). The development of such theories of change can make assumptions explicit, illuminate trade-offs and synergies, inform management and decisionmaking, and support evidence-based policy development (Chervier et al. 2020). Future application of ILAs will need to include thorough ecological knowledge and considerations in this process and ensure that this knowledge is relevant and accessible to other stakeholders, sectors, and disciplines. Indeed, ILAs must seek to reconcile different knowledge systems and scales of governance and build broader alliances that integrate expertise from local stakeholders, ecologists, as well as professionals from other disciplines and sectors.

\section{Conclusion}

Integrated landscape approaches are conceptually appealing and have rapidly gained support across sectors as they offer significant potential for reconciling multiple land use objectives on the ground. It appears that they will be increasingly important as commitments are made to biodiversity conservation through the upcoming Convention on Biological Diversity's Global Biodiversity Framework and forest landscape restoration through the UN decade on ecosystem restoration and Bonn challenge. However, we argue that recent scholarship and discourse have tended to overlook the ecological dimension and inadequately consider potential trade-offs and synergies. Future efforts to implement ILAs must be cognizant that embracing integration across its many dimensions will be key to progress. 
Implementation of ILAs is highly contextualized but general principles can still apply. Application needs to be based on a solid understanding of past trends and current threats and actions need to have local relevance. A greater focus on the ecology of landscape approaches is necessary to enhance understanding of the functioning of landscapes through pattern/process dynamics and ensure that this is better incorporated within land-use decision-making. Meanwhile, greater integration of local socio-economic (and political) dimensions is necessary to shine a light on local lived realities and deliver on the promise of ILAs to be truly integrative.

We hope that by raising this issue and providing some general design suggestions, we can support and incentivise the re-integration of ecology into ILAs and supplement existing design principles. Furthermore, we welcome and encourage greater discussion across communities working on landscape-scale conservation and development as we consider there to be as yet unrealized synergies between the ILA, landscape ecology, landscape governance and knowledge coproduction communities that could elevate their respective (and collective) contributions towards enhancing landscape sustainability.

Author contributions All authors contributed to this manuscript.

Funding This article is part of the CGIAR Research Program on Forests, Trees and Agroforestry (CRP-FTA). This collaborative program aims to enhance the management and use of forests, agroforestry and tree genetic resources across the landscape from forests to farms. Funding was provided by the International Climate Initiative (IKI) of the Federal Ministry for the Environment, Nature Conservation, Building and Nuclear Safety (BMUB) Grant 18_IV_084, the United States Agency for International Development (USAID) Forest and Biodiversity Office and the CGIAR FTA program. R.C. was supported by the Frank Jackson Foundation.

\section{Declarations}

Conflict of interest The authors declare no conflicts of interest.

Open Access This article is licensed under a Creative Commons Attribution 4.0 International License, which permits use, sharing, adaptation, distribution and reproduction in any medium or format, as long as you give appropriate credit to the original author(s) and the source, provide a link to the Creative Commons licence, and indicate if changes were made. The images or other third party material in this article are included in the article's Creative Commons licence, unless indicated otherwise in a credit line to the material. If material is not included in the article's Creative Commons licence and your intended use is not permitted by statutory regulation or exceeds the permitted use, you will need to obtain permission directly from the copyright holder. To view a copy of this licence, visit http://creativecommons.org/licenses/by/4.0/.

\section{References}

Adams WM et al (2004) Biodiversity conservation and the eradication of poverty. Science 306(5699):1146-1149

Antrop M (2000) Background concepts for integrated landscape analysis. Agric Ecosyst Environ 77(1-2):17-28

Antrop M (2006) Sustainable landscapes: contradiction, fiction or utopia? Landsc Urban Plan 75(3-4):187-197

Arroyo-Rodriguez V et al (2020) Designing optimal humanmodified landscapes for forest biodiversity conservation Designing optimal human-modified landscapes for forest biodiversity conservation. Ecol Lett. https://doi.org/10. 1111/ele.13535

Arts B et al (2017) Landscape approaches: a state-of-the-art review. Annu Rev Environ Resour 42:439

Balint PJ, Stewart RE, Desai A (2011) Wicked environmental problems: managing uncertainty and conflict. Island Press, Washington, DC

Ban NC et al (2018) Incorporate indigenous perspectives for impactful research and effective management. Nat Ecol Evol 2(11):1680

Barlow J et al (2011) Using learning networks to understand complex systems: a case study of biological, geophysical and social research in the Amazon. Biol Rev $86(2): 457-474$

Barlow J et al (2018) The future of tropical hyperdiverse ecosystems. Nature 559:517

Bennett NJ (2016) Using perceptions as evidence to improve conservation and environmental management. Conserv Biol 30(3):582-592

Biggs D et al (2011) The implementation crisis in conservation planning: Could "mental models" help? Conserv Lett 4(3):169-183

Boedhihartono AK et al (2018) Conservation science and practice must engage with the realities of complex tropical landscapes. Trop Conserv Sci 11:194008291877957

Bourgeron P, Humphries HC, Jensen ME (2001) Ecosystem characterization and ecological assessments. In: Jensen ME, Bourgeron PS (eds) A guidebook for integrated ecological assessments. Springer, New York, NY, pp 40-54

Bousquet $F$ et al (2002) Multi-agent systems and role games: an approach for ecosystem co-management. In: Janssen M (ed) Complexity and ecosystem management: the theory and practice of multi-agent approaches. Elgar Publishers, Northampton, pp 248-285

Brown K (2003) Integrating conservation and development: a case of institutional misfit. Front Ecol Environ 1(9):479-487

Brown K (2004) Trade-off analysis for integrated conservation and development. In: McShane TO, Wells MP (eds) 
Getting biodiversity projects to work. Columbia University Press, New York, pp 232-255

Bürgi M et al (2017) Integrated landscape approach: closing the gap between theory and application. Sustainability. https:// doi.org/10.3390/su9081371

Büscher B, Fletcher R (2019) Towards convivial conservation. Conserv Soc 17(3):283-296

Carmenta R et al (2020) Characterizing and evaluating integrated landscape initiatives. One Earth 2(2):174-187

Cash DW et al (2003) Knowledge systems for sustainable development ". Proc Natl Acad Sci USA 100(14):8086-8091

Cash DW et al (2006) Scale and cross-scale dynamics: Governance and information in a multilevel world. Ecol Soc 11(2):8

Castaneda F, Palmberg-Lerche C, Vuorinen P (2001) Criteria and indicators for sustainable forest management: a compendium. Forest Management Working Paper (FAO)

Charnley S et al (2017) Evaluating the best available social science for natural resource management decision-making. Environ Sci Policy 73(April):80-88

Chazdon RL et al (2020) Co-creating conceptual and working frameworks for implementing forest and landscape restoration based on core principles. Forests 11(6):1-24

Chervier C, Piketty MG, Reed J (2020) Theories of change and monitoring and evaluation types for landscape approaches. In: Reed J, Ros-Tonen MAF, Sunderland T (eds) Operationalizing integrated landscape approaches in the tropics. CIFOR, Bogor, p 78

Christensen J (2004) Win-win illusions. Conserv Pract $5(1): 12-19$

Clay N (2016) Geoforum producing hybrid forests in the congo basin: a political ecology of the landscape approach to conservation. Geoforum 76:130-141

Collier N et al (2011) Science for action: the use of scoping models in conservation and development. Environ Sci Policy 14(6):628-638

Cordingley JE et al (2016) Can landscape-scale approaches to conservation management resolve biodiversity-ecosystem service trade-offs? J Appl Ecol 53(1):96-105

Cunningham RB, Lindenmayer DB (2017) Approaches to landscape scale inference and study design. Curr Landsc Ecol Rep. https://doi.org/10.1007/s40823-016-0019-4

Daw TM et al (2015) Evaluating taboo trade-offs in ecosystems services and human well-being. Proc Natl Acad Sci USA 112(2):6949-6954

DeFries R, Rosenzweig C (2010) Toward a whole-landscape approach for sustainable land use in the tropics. Proc Natl Acad Sci 107(46):19627-19632

Djenontin INS, Meadow AM (2018) The art of co-production of knowledge in environmental sciences and management: lessons from international practice. Environ Manage 61(6):885-903

Doak DF et al (2013) What is the future of conservation? Trends Ecol Evol 29:77

Dornelas M, Magurran AE (2018) BioTIME: a database of biodiversity time series for the Anthropocene. Global Ecol Biogeogr 27(November 2017):760-786

Erbaugh JT, Agrawal A (2017) Clarifying the landscape approach: a letter to the Editor on "Integrated landscape approaches to managing social and environmental issues in the tropics." Global Change Biol. https://doi.org/10.1111/ ijlh.12426

ESPA (2018) Wellbeing:for whom and how? ESPA, Farnham

Esquivel-Muelbert A et al (2019) Compositional response of Amazon forests to climate change. Global Change Biol. https://doi.org/10.1111/gcb.14413

Evans K et al (2021) Getting it right: a guide to improve inclusion in multi-stakeholder forums. CIFOR, Bogor

Evans K, Guariguata MR, Brancalion PHS (2018) Participatory monitoring to connect local and global priorities for forest restoration. Conserv Biol 32(3):525-534

Ferreira J et al (2018) Carbon-focused conservation may fail to protect the most biodiverse tropical forests. Nat Clim Change 8(8):744-749

Fischer J, Lindenmayer DB, Manning AD (2006) Biodiversity, ecosystem function, and resilience: ten guiding principles for commodity production landscapes. Front Ecol Environ $4(2): 80-86$

Fischer J et al (2008) Should agricultural policies encourage land sparing or wildlife-friendly farming? Front Ecol Environ 6(7):380-385

Foley JA et al (2011) Solutions for a cultivated planet. Nature 478(7369):337-342

Fonseca MG et al (2019) Effects of climate and land-use change scenarios on fire probability during the 21 st century in the Brazilian Amazon. Global Change Biol 25(9):2931-2946

França F et al (2016) Do space-for-time assessments underestimate the impacts of logging on tropical biodiversity? An Amazonian case study using dung beetles. J Appl Ecol 53(4):1098-1105

França FM et al (2020) Climatic and local stressor interactions threaten tropical forests and coral reefs. Philos Trans R Soc B 375:20190116

Freeman OE, Duguma LA, Minang PA (2015) Operationalizing the integrated landscape approach in practice. Ecol Soc 20(1):24ff

Gardner T et al (2008) The cost-effectiveness of biodiversity surveys in tropical forests. Ecol Lett 11:139-150

Gergel S et al (2020) Conceptual links between landscape diversity and diet diversity: a roadmap for transdisciplinary research. Bioscience 70(7):563-575

Godfray HCJ et al (2010) Food security: the challenge of feeding 9 billion people. Science (new York, n. y.) 327(5967):812-818

Gomes L, Miranda HS, da Cunha Bustamante MM (2018) How can we advance the knowledge on the behavior and effects of fire in the Cerrado biome? For Ecol Manage 417:281-290

Guariguata MR, Evans K (2019) 'A diagnostic for collaborative monitoring in forest landscape restoration. Restor Ecol. https://doi.org/10.1111/rec.13076

Gurney GG et al (2019) Implementing a social-ecological systems framework for conservation monitoring: lessons from a multi-country coral reef program. Biol Conserv 240(August): 108298

Gutzwiller K (2002) Applying landscape ecology in biological conservation. Springer, New York

Hart AK et al (2015) Integrated landscape initiatives in practice: assessing experiences from 191 landscapes in Africa nad Latin America. In: Minang PA et al (eds) Climate-smart 
landscapes: multifunctionality in practice. World Agroforestry CEntre, Nairobi, pp 89-102

Hicks CC et al (2016) Engage key social concepts for sustainability. Science 352(6281):38-40

IPBES (2019) Global assessment report on biodiversity and ecosystem services of the Intergovernmental Science Policy Platform on Biodiversity and Ecosystem Services. Bonn, Germany

Jenerette GD, Shen W (2012) Experimental landscape ecology. Landsc Ecol 27(9):1237-1248

Kimmerer RW (2013) Braiding sweetgrass: indigenous wisdom, scientific knowledge and the teachings of plants. Milkweed Editions, Minneapolis

Kozar R et al (2014) Toward viable landscape governance systems: what works? EcoAgriculture Partners, on behalf of the Landscapes for People, Food, and Nature Initiative, Washington, DC

Kremen C, Merenlender AM (2018) Landscapes that work for biodiversity and people. Science. https://doi.org/10.1126/ science.aau6020

Kusters K et al (2018) Participatory planning, monitoring and evaluation of multi-stakeholder platforms in integrated landscape initiatives. Environ Manage 62(1):170-181

Kusters K et al (2020) Inclusive landscape governance for sustainable development: assessment methodology and lessons for Civil Society Organizations. Land 9(4):128

Lang DJ et al (2012) Transdisciplinary research in sustainability science: practice, principles, and challenges. Sustain Sci 7:25-43

Langemeyer J et al (2018) Participatory multi-criteria decision aid: operationalizing an integrated assessment of ecosystem services. Ecosyst Serv 30:49-60

Larson A et al (in review) Hot topics in governance for forests and trees: towards a (just) transformative research agenda. Forest Policy and Economics

Laumonier Y, Bourgeois R, Pfund J (2008) Accounting for the ecological dimension in participatory research and development: lessons learned from Indonesia and Madagascar. Ecol Soc 13(1):15

Laurance WF et al (2011) The fate of Amazonian forest fragments: a 32-year investigation. Biol Conserv 144(1):56-67

Leal CG et al (2020) Integrated terrestrial-freshwater planning doubles conservation of tropical aquatic species. Science 121(October):117-121

Lebel L (2013) Local knowledge and adaptation to climate change in natural resource-based societies of the Asia-Pacific. Mitig Adapt Strateg Global Change. https://doi.org/ $10.1007 / \mathrm{s} 11027-012-9407-1$

Lindenmayer D et al (2008) A checklist for ecological management of landscapes for conservation. Ecol Lett 11(1):78-91

Lockwood M et al (2010) Governance Principles for Natural Resource Management Governance Principles for Natural Resource Management. Soc Nat Resour 1920:986-1001

Loschiavo AJ et al (2013) Lessons learned from the first decade of adaptive management in comprehensive everglades restoration. Ecol Soc 18(4):11

Mace G (2014) Whose conservation? Science 345(6204): 1558

Mansourian S (2017) Governance and forest landscape restoration: a framework to support decision-making. J Nat Conserv 37:21-30
Mansourian S (2018) In the eye of the beholder: reconciling interpretations of forest landscape restoration. Land Degrad Dev. https://doi.org/10.1002/ldr.3014

Mansourian S (2021) From landscape ecology to forest landscape restroration. Landsc Ecol 3:1-10

Mansourian S, Parrotta JA (2018) Forest landscape restoration: integrated approaches to support effective implementation. Routledge, London

Mansourian S, Sgard A (2019) Diverse interpretations of governance and their relevance to forest landscape restoration. Land Use Policy. https://doi.org/10.1016/j.landusepol. 2019.05.030

Mbow C, Neely C, Dobie P (2015) How can an integrated landscape approach contribute to the implimentation of the Sustainable Development Goals (SDGs) and advance climate-smart objectives? In: Minang PA, van Noordwijk M (eds) Climate-smart landscapes: multifunctionality in practice. World Agroforestry Centre (ICRAF), Nairobi, pp 103-116

McCall MK (2016) Beyond "Landscape" in REDD+: the imperative for "territory." World Dev 85:58-72

Mcneely JA (2006) Agroforestry and biodiversity conservation-traditional practices, present dynamics, and lessons for the future. Biodivers Conserv. https://doi.org/10.1007/ s10531-005-2087-3

McShane TO et al (2011) Hard choices: making trade-offs between biodiversity conservation and human well-being. Biol Conserv 144(3):966-972

Meinig DW (1979) The beholding eye. Ten versions of the same scene. In: Meinig DW (ed) The interpretation of ordinary landscapes. Oxford University Press, New York, pp 33-48

Milder JC et al (2012) Landscape approaches to achieving food production, natural resource conservation, and the millennium development goals. In: Ingram JC, DeClerck F (eds) Integrating ecology and poverty reduction. Springer, Berlin, pp 77-108

Montoya D et al (2020) 'Reconciling biodiversity conservation, food production and farmers' demand in agricultural landscapes. Ecol Model 416:108889

Muradian R et al (2013) Payments for ecosystem services and the fatal attraction of win-win solutions. Conserv Lett 6(4):274-279

Norris K (2008) Agriculture and biodiversity conservation: opportunity knocks. Conserv Lett 1:2-11

Norström AV et al (2020) 'Principles for knowledge co-production in sustainability research. Nat Sustain. https://doi. org/10.1038/s41893-019-0448-2

Noss RF (1983) A regional landscape approach to maintain diversity. Bioscience 33(11):700-706

Oates J (1999) Myth and reality in the rainforest: how conservation strategies are failing in West Africa. University of California Press, Berkeley

Ojha HR, Hall A, Sulaiman VR (2013) Adaptive collaborative approaches in natural resource governance: rethinking participation, learning and innovation. Routledge, London

Padmanaba M, Sheil D (2013) Accessing local knowledge to identify where species of conservation concern occur in a tropical forest landscape. Environ Manage 52:348-359

Pascual U et al (2021) Biodiversity and the challenge of pluralism. Nat Sustain. https://doi.org/10.1038/s41893-02100694-7 
Phillips O et al (Accepted) Taking the pulse of earth's tropical forests using networks of highly distributed plots. Biol Conserv (In Press)

Qiu J et al (2018) Evidence-based causal chains for linking health, development, and conservation actions. Bioscience. https://doi.org/10.1093/biosci/bix167

Rasmussen LV, Watkins C, Agrawal A (2017) Forest Policy and Economics Forest contributions to livelihoods in changing agriculture-forest landscapes. Forest Policy Econ. https:// doi.org/10.1016/j.forpol.2017.04.010

Reed J et al (2016) Integrated landscape approaches to managing social and environmental issues in the tropics: learning from the past to guide the future. Global Change Biol. https://doi.org/10.1111/gcb.13284

Reed J, van Vianen J, Barlow J et al (2017a) Have integrated landscape approaches reconciled societal and environmental issues in the tropics? Land Use Policy. https://doi. org/10.1016/j.landusepol.2017.02.021

Reed J, van Vianen J, Foli S et al (2017b) Trees for life: The ecosystem service contribution of trees to food production and livelihoods in the tropics. Forest Policy Econ. https:// doi.org/10.1016/j.forpol.2017.01.012

Reed J et al (2019) Engaging multiple stakeholders to reconcile climate, conservation and development objectives in tropical landscapes. Biol Conserv 238(March):108229. https://doi.org/10.1016/j.biocon.2019.108229

Reed J et al (2020a) A methods toolbox for integrated landscape approaches. In: Reed J, Ros-Tonen MAF, Sunderland T (eds) Operationalizing integrated landscape approaches in the tropics. CIFOR, Bogor, p 89

Reed J et al (2020b) Integrated landscape approaches in the tropics: a brief stock-take. Land Use Policy 99(April): 104822

Rietbergen-McCracken J, Narayan-Parker D (1998) Participation and social assessment: tools and techniques. World Bank Publications, Washington, DC

Ros-Tonen MAF, Reed J, Sunderland T (2018) From synergy to complexity: the trend toward integrated value chain and landscape governance. Environ Manage. https://doi.org/ $10.1007 / \mathrm{s} 00267-018-1055-0$

Salwasser H (2002) Navigating through the wicked messiness of natural resource problems: roles for science, coping strategies, and decision analysis. In: Paper presented at the Sierra Science Summit, Kings Beach, CA

Sandbrook C (2015) What is conservation? Oryx 49(4):565-566

Sandbrook C et al (2013) Social research and biodiversity conservation. Conserv Biol 27(6):1487-1490

Sandbrook C et al (2019) The global conservation movement is diverse but not divided. Nat Sustain. https://doi.org/10. 1038/s41893-019-0267-5

Sayer J (2009) Reconciling conservation and development: are landscapes the answer? Biotropica 41(6):649-652

Sayer J, Wells MP (2004) The pathology of projects. In: McShane TO, Wells MP (eds) Getting biodiversity projects to work: towards better conservation and development. Columbia University Press, New York, pp 35-48

Sayer JA, Campbell BM (2004) The science of sustainable development: local livelihoods and the global environment. Cambridge University Press, Cambridge

Sayer J, Campbell EB, Petheram EL (2006) Assessing environment and development outcomes in conservation landscapes. Biodivers Conserv. https://doi.org/10.1007/ s10531-006-9079-9

Sayer J et al (2013) Ten principles for a landscape approach to reconciling agriculture, conservation, and other competing land uses. Proc Natl Acad Sci USA 110(21):8349-8356

Sayer J et al (2015a) The role of citizen science in landscape and seascape approaches to integrating conservation and development. Land 4:1200-1212

Sayer J, Margules C, Boedhihartono AK, Dale A, Sunderland T, Supriatna J, Saryanthi R (2015) Landscape approaches; what are the preconditions for success? Sustainability Science 10(2):345-355

Sayer JA et al (2016) Measuring the effectiveness of landscape approaches to conservation and development. Sustain Sci. https://doi.org/10.1007/s11625-016-0415-z

Scherr SJ, McNeely JA (2008) 'Biodiversity conservation and agricultural sustainability: towards a new paradigm of "ecoagriculture" landscapes. Philos Trans R Soc Lond B Biol Sci 363(1491):477-494

Scherr S, Shames S, Friedman R (2013) Defining integrated landscape management for policy makers. EcoAgric Policy Focus 10:1-6

Sheil D, Lawrence A (2004) Tropical biologists, local people and conservation: new opportunities for collaboration. Trends Ecol Evol 19(12):634-638

Sheil D, Nasi R, Johnson B (2004) 'Ecological Criteria and indicators for tropical forest landscapes: challenges in ecological criteria and indicators for tropical forest landscapes: challenges in the search for progress. Ecol Soc. https://doi.org/10.5751/ES-00638-090107

Shettima A, Tar U (2008) Farmer-pastoralist conflict in West Africa: exploring the causes and consequences. Inf Soc Justice J 1(2):163-184

Solar R et al (2015) How pervasive is biotic homogenization in human-modified tropical forest landscapes? Ecol Lett 18:1108-1118

Soulé M (2013) The "new conservation." Conserv Biol 27(5):895-897

Star SL, Griesemer J (1989) 'Institutional ecology, translations' and boundary objects: amateurs and professionals in Berkeley's Museum of Vertebrate Zoology 1907-39. Soc Stud Sci 19(3):387-420

Stouffer PC et al (2021) Long-term change in the avifauna of undisturbed Amazonian rainforest: ground-foraging birds disappear and the baseline shifts. Ecol Lett 24(2):186-195

Sueur J, Farina A (2015) Ecoacoustics: the ecological investigation and interpretation of environmental sound. Biosemiotics 8:493-502

Sunderland $\mathrm{T}$ et al (2017) A methodological approach for assessing cross-site landscape change: understanding socio-ecological systems. Forest Policy Econ 84(May):83-91

Sunderland TCH, Ehringhaus C, Campbell BM (2008) Conservation and development in tropical forest landscapes: a time to face the trade-offs? Environ Conserv 34(4):276-279

Synes NW et al (2016) emerging opportunities for landscape ecological modelling. Curr Landsc Ecol Rep 1:146-167

Tress B et al (2001) Bridging human and natural sciences in landscape research. Landsc Urban Plan 57(3-4):137-141 
Tscharntke T et al (2012) Global food security, biodiversity conservation and the future of agricultural intensification. Biol Cons 151(1):53-59

Vermunt DA, Verweij PA, Verburg RW (2020) What hampers implementation of integrated landscape approaches in rural landscapes? Curr Landsc Ecol Rep 5:99

Voinov A et al (2018) Environmental modelling \& software tools and methods in participatory modeling: selecting the right tool for the job. Environ Model Softw 109(August):232-255
Wu JG (2013) Key concepts and research topics in landscape ecology revisited: 30 years after the Allerton Park workshop. Landsc Ecol 28(1):1-11

Zafra-calvo N et al (2020) Plural valuation of nature for equity and sustainability: insights from the Global South. Global Environ Change 63(April):102115

Publisher's Note Springer Nature remains neutral with regard to jurisdictional claims in published maps and institutional affiliations. 